\title{
Docencia arquitectónica en globalización: ¿Prevalencia, filtro o anulación del perfil local de identidad?
}

\author{
Sofía Letelier Parga
}

\section{Filiación}

Arquitecta, Profesora Asociada U. Chile. Docente al Guadalajara, México hasta 1971, y en San Luis de Potosí hasta 1979, donde es coautora del Plan de Estudios de la Escuela de Arquitectura del Estado y hasta hoy, Maestra Visitante. En investigación se ha especializado Metodología del Diseño y Creatividad, materia sobre la que ha realizado publicaciones de artículos, y libros. Es coautora de Prenorma para Discapacitados Físicos. Evaluadora externa de Fondecyt, y diversas Universidades del país. Fue evaluadora del Board de la RIBA en 1990 para Sheffield. Ha sido Directora del Instituto de la Vivienda, Directora Académica y Directora de Pregrado. Desde 2000, es Miembro del Consejo Normativo de la Universidad de Chile.

\section{Resumen}

El presente artículo desarrolla con mayor detalle las ideas acerca de la docencia arquitectónica en momentos de globalización, que fueran planteadas al $\mathrm{V}$ Congreso Arquisur como derivación de la línea investigativa sobre 'Identidad Arquitectónica' bajo un enfoque semiótico. La investigación realizada entre 1993 -1996 con financiamiento Fondecyt y que contó con la co-investigación de María Inés Arribas y Ana Rugiero, permitió detectar algunos rasgos de interpretación local que operan entre arquitectos y legos, los que pueden estimarse como indicadores de lectura visual de la arquitectura, a la vez que modeladores 'autopoïéticos' de un perfil de Identidad Arquitectónica en Chile central. Éstos, que resultaron no siempre coincidentes con el cannon de valoración académico escolar, instalan la interrogante sobre la posibilidad de explicitarlos y manejarlos conscientemente para asumir la globalización desde el valor de la diferencia, o bien desligarse de su presencia, favoreciendo una más flexible apertura a la homologación de expresiones. Desde la hipótesis de que la arquitectura es un lenguaje y sistema social, cuyos códigos no escapan al circuito de experiencia y noción en cuyo desfase se da todo lenguaje, se postula la existencia de patrones locales generales -comprobados en Chile central- aun cuando se hayan detectado códigos particulares y específicos distintos para legos y arquitectos, que muestren reducidos campos de intersección. En éstos, y en la tendencia general de ambas constelaciones, pudo encontrarse un definido perfil de Identidad. Resta comprobar si hay ánimo académico de asumirlo como factor proactivo.

\section{Palabras claves}

Docencia en arquitectónica, identidad arquitectónica.

\begin{abstract}
This paper develops in greater detail the ideas about teaching architecture at a time of globalization. The research conducted between 1993 -1996, financed by FONDECYT and had the co - investigation and Ana María Inés Arribas Rugiero allowed the
\end{abstract}


detection of some local features of operating performance between architects and laymen, which can be estimated as indicators of visual architecture, while modelers 'autopoietic' a profile of Architectural Identity in central Chile.

\section{Key words}

Teaching architectural, architectural identity.

\section{Sumario}

Introducción

Docencia y lenguaje

Dilemas de la docencia descentrada

Principales rasgos de identidad

1.- La 'DESAGREGACIÓN' permite cualquier agregación

2.- Vocación por LO IDÉNTICO por sobre LO IDENTIFICABLE

3.- Contemporaneidad por PARECER más que por 'SER'

4.- EI REMATE SUPERIOR es el signo más interpelante y significante para el chileno

5. EI CLIMA NO ES EN CHILE CENTRAL UN INDUCTOR de codificación ni de decodificación

6. La economía de los 'LUSTRINES', su truncamiento como RASGO PROPIO

7.- SIMPLIFICACIÓN SIGNIFICATIVA REDUCTIVA

\section{Introducción}

Hay que reconocer que la 'identidad' tiene hoy cada vez más sentido como término de intercambio y soporte a la autoafirmación para una integración fructífera en diversos ámbitos. Abordada con mayor rigor en la arquitectura y su enseñanza, la Identidad puede dejar de ser una palabra adjetiva o una vaga sensación - reactiva cuando admiramos un entorno al que atribuimos "carácter" - pudiendo transformarse en herramienta operativa de proyecto y validarse metódicamente a partir del aporte de las ciencias sociales, como es el caso de la semiótica.

Nuestra docencia acostumbrada a una contraposición entre homogenización global o regional y la cultura local - con una temida hegemonía de la primera en tiempos de globalización-, pone en crisis pero también en el centro del problema el estado de valor de la Identidad: el grado en que existe, cuando existe ; su consistencia; su nivel de clausura o permeabilidad; su capacidad para resistir influencias o para acogerlas, filtrarlas y procesarlas, y, en último término, consciencia de su estado de agotamiento o, derechamente, un rechazo y un complejo de ser y hacer de un cierto modo.

La inminencia de una fluida integración entre países de MERCOSUR y consecuentemente de una creciente colaboración de sus profesionales y arquitectos, 
hace pertinente entre nosotros preguntarse por el valor de la Identidad Arquitectónica particular. El intercambio que se avecina no debiera limitarse a la acepción que remite a facilidad de 'sustitución' -aleatoria de contribuciones locales, en que la homogeneidad las haría indiferentes-, sin llegar a aprovechar ese recíproco brindarse, aquello que el otro carece. Porque el verdadero intercambio (y el mercado mismo) no se produce obviamente entre quienes poseen lo mismo; la noción misma de intercambio supone aprovechar las diferencias.

Pero esas diferencias en lo arquitectónico chileno, esa Identidad Arquitectónica nuestra, pese a ser profusamente mencionada en el medio disciplinar como lugar común o un dado axiomático, no había sido sistemáticamente descrita para enfrentar un escenario que, más allá de la peligrosa sustitución o desperfilamiento entrópico, fructificase en formas de colaboración, complementación y sinergia regional. Porque hasta recientemente, no sabíamos a ciencia cierta que era en el presente 'lo chileno' de nuestra arquitectura para legos y arquitectos; y, aún detectados en la Universidad de Chile sus rasgos básicos para la zona central del país, su transferencia y reflexión en la docencia no encontraba causes por estar insuficientemente procesado y difundido.

Este es un primer intento de sistematizar e interpretar -con miras a reforzar una docencia consciente de nuestra real Identidad Arquitectónica-, los rasgos locales encontrados, no obstante que como se verá, ellos no siempre coinciden con los cánonnes de la visualidad estética disciplinar, acostumbrada a nutrirse en gran medida de las vanguardias imperantes en los centros hegemónicos de producciones más prestigiosa.

\section{Docencia y lenguaje}

La docencia de la arquitectura en nuestro medio se ha separado crecientemente de la 'realidad real'; tempranamente el imaginario del estudiante se puebla de imágenes exógenas que aporta la infografía, que modula los patrones de selectividad y valoración visual con una sensibilidad extraña que tiende a ignorar y hasta desvalorar lo circundante haciéndolo invisible, profundizando el desfase natural de la formación de todo lenguaje al alejar los referentes que debe proporcionar la experiencia a la noción.

Se postula hoy que entre las nociones con que enfrentamos la realidad y los perceptos que construimos a partir de su lectura experiencial, existiría un circuito en continuum en que ambos iteran, informando y formando todo lenguaje. Éste se genera supliendo ese desfase donde es absolutamente necesaria la experiencia (R. Araya, 2000), y en su operación actualizante, se nutre constantemente por una parte, de nuestras 'representaciones semánticas' (significados sociales) y, por otra, de las 'presentaciones' o imágenes (idea personal) que reúne experiencia, sensación y emoción con que operamos esa realidad (Aage Brandt, 2000). Hemos construido un gráfico para explicarlo. 


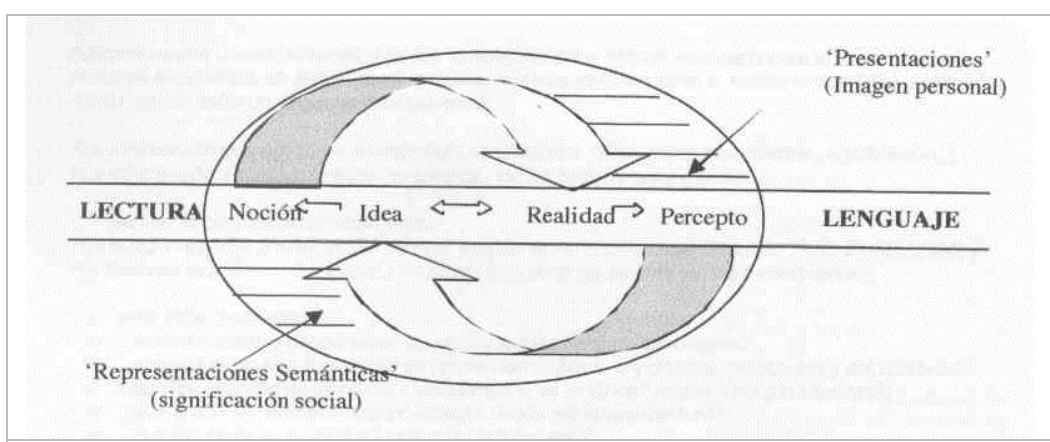

Fig.1.- Circuito en continuum entre nociones y perceptos.

Los 'perceptos' (registro más su sentido) adquieren significación por la experiencia e informan determinada 'idea' de la realidad, idea que a su vez se asienta en nociones ( más estables), con las que interpretamos dicha realidad. Todo lenguaje - y su lectura, en el caso de lenguaje visual- es la sistematización de los mecanismos en dichos desfases, sistematización contextualizada culturalmente.

Ello explica que resulte tan difícil el hablar bien y, especialmente, crear e innovar en una lengua que no es la materna, haciéndose necesario interiorizarse culturalmente en ella hasta comprender cómo se 'piensa' en el otro idioma para usarlo con soltura. Pero como dicho 'pensamiento' no es un abstracto descontextualizado, sino que es producto y efecto de un determinado paisaje físico y social experienciado en un tiempo cultural, siempre tendrá misterios para quien es ajeno o advenedizo. De aquí que, sin más, adoptar y adaptar signos de otros lenguajes, sin haber sido cómplice social en la generación de su proceso significativo, resta control al mensaje y eficacia a la comunicación. (Parece coherente que sea más fácil aprender un segundo idioma en la infancia, cuando las dos vertientes del lenguaje están más plásticas: las nociones están menos formalizadas y hay menor bagaje propio en el nivel perceptual, experiencial).

Lo anterior sería aplicable al aprendizaje y uso de lenguajes no verbales entre los que se encuentran aquellos que, como la arquitectura, están destinados a la inteligencia visual. Éste operaría como sistema de signos y significados que, si bien tienen emisor identificable -el arquitecto, quien personaliza y particulariza el mensaje-, no escapa una vez construido al circuito social más amplio de nociones/ perceptos locales, al independizarse la obra y hacerse a su vez estímulo en determinado paisaje visual colectivo, marco geográfico y lumínico. Constataciones aportadas por la filosofía de la historia, en cuanto a que, por ejemplo, las construcciones de mayor altura han surgido en planicies bastas; o que la articulación de relieves lineales horizontales han favorecido en latitudes soleadas e, inversamente, las verticales, confirman esta mecánica contextualizada del lenguaje.

Ello pone de relieve la importancia de la Identidad -y de una consciencia sobre la misma- ya que toda operación de lenguaje pasa por un 'yo'. Todo lenguaje necesita el sentido del Yo porque se instala para comunicar entre un 'Yo y un otro', haciendo de su 
creación y uso asuntos identitarios. Pero conocer las diferencias de ese Yo, o del 'desde aquí' -rasgos diferenciadores individuales o grupales- demanda develar y aceptar nuestra identidad real, no imaginaria, esa "distinción con todo otro" (M. Vaisman, 1990). Entonces, si el lenguaje (codificación) y la lectura (decodificación) requieren de Identidad para ofrecer estabilidad a ese espacio de desplazamiento (entre 'realidad real y realidad percibida; y al intersticio entre 'noción' permanente e idea particular) desde la que se emite, el repertorio de imágenes que llamamos 'Imaginario' y su sistematización en un Lenguaje, son a su vez particulares desplazamientos sociales a la vez que efectos de Identidad. De no haberla o ser difusa, dicho proceso se dificulta.

\section{Dilemas de la docencia descentrada}

Adicionalmente a este universal y primer desplazamiento mental necesario para articular lenguaje, nuestros estudiantes de arquitectura en estos mundos descentrados o 'exocéntricos' (M.I. Arribas, 1993), deben sufrir un segundo desfase entre:

- La información perceptual de su realidad (arquitectura, clima, geografía, historia, significación) y

-La información visual fotográfica -mediática- de los centros prestigiosos.

...Y aún un tercer desplazamiento entre:

- La cultura espacial ancestral, del exterior mapuche, no positivizado (Maulen, 1996; Flores, 2000) y

-El discurso académico disciplinar.( un orden formal de pautas, de vacíos formalizados)

Y en este triple deslizamiento:

a) ¿Cómo ciframos y desciframos los textos arquitectónicos localmente?

b) ¿Con qué extensión o clausura se operan los códigos importados, heredados y del contexto?

c) ¿Qué tipo y grado de identidad / identificación se produce? (estructural o actitudinal?)

d) ¿Qué grado de 'comunicación' alcanza desde allí la arquitectura?

e) ¿Qué tan consciente está la Docencia de todo ello?

Luego cabe preguntarse en primer lugar, si en la región y en Chile estamos conscientes -los arquitectos y las escuelas de arquitectura- del repertorio de nociones / perceptos que informan nuestros códigos, aquellos conque ciframos y desciframos el mundo construido. En segundo lugar, si dichos códigos o algunos se mantienen compartidos y valorados por todos localmente -como en aquellos lugares en que 
perdura un 'carácter'- y, si es el caso, cuáles son esas tendencias locales y cómo hacerlas explícitas. En tercer lugar, cómo operan y han operado dichos códigos locales en la selección, adaptación y adopción de signos foráneos y en el proceso de significación local, ya que el significado original nos será esquivo. $Y$, por último, si es conveniente para los docentes y si están dispuestos a reconocer este substrato que actuaría de filtro frente a otros 'idiomas' de este lenguaje, o bien ignorarlo para favorecer una fluidez hacia expresiones alusivas a contemporaneidad, aun sabiendo que habrá limitado éxito.

Suponiendo que toda comunicación se alcanza en un plano de códigos solidarios, se buscó en nuestra investigación la presencia y el estado de códigos locales de decodificación de obras entre Legos y Arquitectos; patrones locales y cuáles de ellos promovían alguna clase de 'comunicación' previsible, ya que la docencia es una hipótesis de lo previsible. Interesaba conocer, no la comunicación entre -o paraarquitectos, sino entre Legos y arquitectura.

\section{Principales rasgos de identidad}

Dentro de varios rasgos que se estima estarían en la base de la Identidad arquitectónica ambiente, cabe destacar algunos a los que se puede atribuir conceptualmente incidencia en la orientación de esos vínculos que se establecen en primer nivel de deslizamiento para la generación de lenguaje, es decir los que procesan la realidad y producen ideas. (La metodología semiótica se aplicó frente a pares de estímulos fotográficos, a partir de la verbalización de adjetivos y su posterior análisis semiológico).

1. Identidad 'ACTITUDINAL ': empleamos este término para expresar que no resulta distintivo entre nosotros el signo (arquitectónico) que se usa sino cómo se usa; que no se evidencia una producción local de signos originales ni una clara vocación al empleo consistente de determinados signos y códigos, sino que se advierte una convergencia de actitud en varios aspectos:

Actitudianal sígnico = profusión de signos y tipos, variaciones, autoreferencias. Actitudinal visémica $=$ versiones de cada tipo por variación de atributos, hasta afectar su estructura.

Actitudinal espacial = espacio urbano residual, no positivizado, no 'apropiado'. Actitudinal sintáctico = desagregación de códigos que los abre a la agregación. Actitudinal en instancia de lectura = sobresimplificación.

Si bien en cada nivel semático (Accesos, Remates Superiores y Esquinas o Envolvente) se detectó una variada tipología y aleatoria elección de uso, se advierte una convergencia en pocos tipos (macrotipos) preferentes por ciudades, pero su tratamiento los desperfila como tales.

2. DÉBIL VÍNCULO COMUNICACIONAL EMISOR/ RECEPTOR: se detectó una considerable distancia entre el campo noético de significados que maneja el Arquitecto y el del Lego, y la escasa coincidencia no se encuentra en el valor sino en el disvalor. 
La comunicación mediante este lenguaje se ve dificultada por:

Amplias Divergencias = respectivos 'imaginarios' difieren en un $60 \%$ Claras Discrepancias $=$ respectivos 'imaginarios' se oponen en un $25 \%$ Escasa Intersección = área de posible comunicación no mayor del 6,5\% Motivaciones paralelas $=$ campos significantes propios, distintos referentes $\mathrm{y}$ contenidos para los significados que pudieran coincidir.

Se hace evidente un grado de incomunicación de y por la arquitectura, cuando más de la mitad del campo de contenidos del emisor y del receptor habitan 'mundos distintos' y cuando una cuarta parte se instala incluso en 'mundos opuestos'; y aún más cuando existe, aunque reducido, un campo de significados comunes pero éste es en gran medida aparente por obedecer a motivaciones y referencias paralelas.

3. Campos noéticos POSITIVOS de DISTINTO SIGNO: yendo a lo medular del proceso de significación, la valoración; y aun siendo estrecha el área de potencial comunicación, pudimos encontrar el campo de preferencias que orientan positivamente hacia el enunciado arquitectónico. Los contenidos positivos de ambos grupos, difieren: es más amplio y rico el mundo de contenidos del Lego.

Lego $=$

f) Su adjetivación es amplia y se orienta por experiencia y sensación

g) Establece diferencia ideáticas respecto de localidad, clima y emplazamiento

h) Coinciden en lo que prefieren y también en lo que rechazan.

Arquitecto $=$

a) Su adjetivación escueta y se orienta sólo por atributos formales, evitando la sensación.

b) Prefiguraciones nocionales respecto de localidad y clima.

c) No coinciden en lo que prefieren, sí en lo que rechazan.

La intersección positiva coincidente estuvo dada por las nociones de 'acogida', 'protección', 'seguridad', 'apertura', 'liviandad', 'sobriedad' y 'elegancia', conjunto que en sí mismo perfila una imagen capaz de generar lenguaje. (Los últimos adjetivos se aplican también coincidentemente a color, aunque el Lego agrega la expectativa de 'alegre').

4. Coincidencias EN LO NEGATIVO: frente al hecho de que lo único coincidente entre arquitectos resultó ser lo que rechazan, fue importante constatar que ello coincidía con lo que también el Lego considera negativo. Ello resultó ser lo que les resulta 'frío' y/o 'feo'. Si bien este último fue de indeterminada aplicación, es alentador que ambos grupos mostraran en ello alta coincidencia. (Había que profundizar los atributos que inducen la reacción y que muchas veces estuvo asociado, a la vez, a 'frío'). En la especificación de este par común y en identificar sus antónimos pudiera estar el germen del lenguaje local. 
Teniendo presente estos cuatro rasgos de base y su traducción en obras, como se expone a continuación, se pueden formular hipótesis de docencia.

\section{RASGOS TRADUCIDOS EN LO CONSTRUIDO Y REFLEXIÓN DOCENTE. *}

* (Los ejemplos y las imágenes que se utilizan a continuación hacen parte de un estudio tipológico correspondiente a los 'macrotipos', en sus versiones en edificios de altura para el estudio del Imaginario Loca I, que fueran publicadas en la Revista de Urbanismo No 4. Se comentan aquí como herramienta pedagógica).

1.- La 'DESAGREGACIÓN' permite cualquier agregación: Lo desagregado fue reconocido consistentemente como 'chileno' por Legos y Arquitectos, en todos los pares de estímulos de la encuesta visual, de donde se deduce que puede asumirse como 'nuestra' esta característica. Denominamos así a los cuerpos cuya estructura es de difícil recuerdo y que presentan dificultad para su descripción sintética, lo que habla de un alejamiento de una de las primeras leyes de la Gestalt, cual es la de la pregnancia, entre otras.
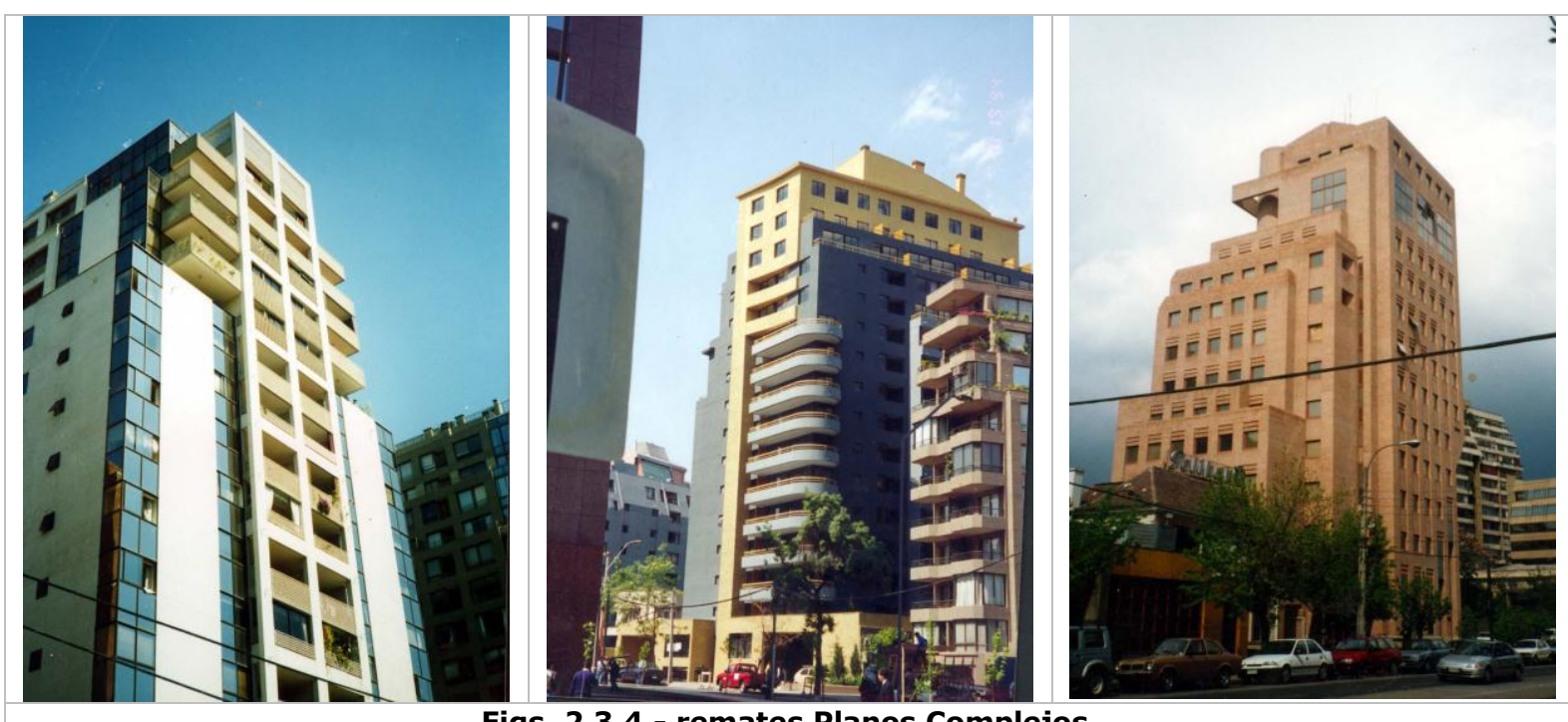

Figs. 2,3,4.- remates Planos Complejos.

¿Podríamos los docentes abordar y lograr el atributo de 'totalidad' a partir de la variedad y de lo desagregado, y no al revés como lo hacemos actualmente que partimos exigiendo PREGNANCIA, COMPLETITUD Y UNIDAD, atributos que se olvidan una vez egresados, por no ser parte de nuestra Identidad?

¿Podremos legitimar y aprender a valorar la variedad desagregada, desde nosotros mismos, desde nuestras expresiones y motivos y no desde la postura POSMODERNA que, por otras razones culturales y filosóficas valida hoy el FRAGMENTO? 
¿Podremos aceptar las formas y mecanismos propios de 'agregación' (hasta ahora aparentemente aleatoria), esa que escolarmente se penaliza aunque después aflora naturalmente en los profesionales?

\section{2.- Vocación por LO IDÉNTICO por sobre LO IDENTIFICABLE}

Se demostró una primacía por apoderarse de un signo a través de lo 'objetual', de lo físico alusivo por sobre el significado; una tendencia a poseerlo en tanto objeto, aun cuando las variaciones locales lo alejen de su referencia. Emisores (arquitectos) muy centrados en el juicio a su erudición disciplinar de evidenciar 'citas' y poco alertas al efecto en el usuario. Si la percepción es 'registro más sentido', en Chile estaríamos más orientados hacia el registro en desmedro del sentido. Hay un reduccionismo en el lenguaje visual que apunta en un primer momento más a rasgos de la sustancia que al código, aunque en el proceso iconoclasta ese rasgo sustancial se desvanezca.

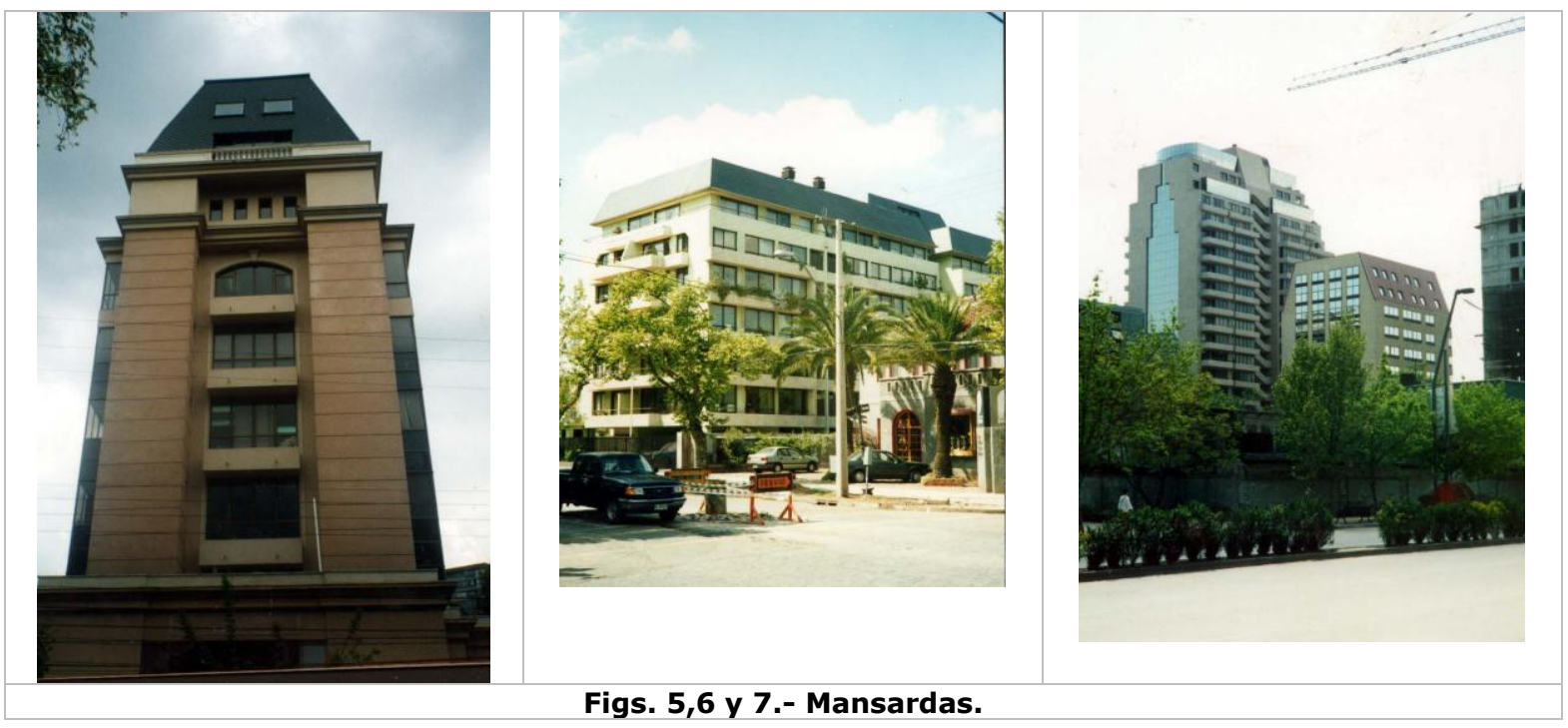

Frente a la elocuencia de los ejemplos cabe preguntarse: ¿Será necesario acentuar la búsqueda de sentido a todo nuestro hacer, o bien reorientar su sentido?

¿Deberemos incrementar el número de desafíos reales en contextos reales, de modo que los estudiantes puedan calibrar el efecto de las decisiones en contextos urbanos determinados? 
¿Deberemos desafiar en mayor medida a los estudiantes con problemas humanos y urbanos a la vez, antes que con 'temas' - que sabemos inducen soluciones por su propia denominación, como 'edificio de habitación'- que perpetúan un cierto conservadurismo en el hacer?

¿Podremos trabajar con los estudiantes en forma consciente e informada los tipos que pueden desprenderse de la información, comprendiendo su estructura esencial para que no funcionen siempre como imágenes 'modelo', en su puro efecto icónico?

\section{3.- Contemporaneidad por PARECER más que por 'SER'}

El deseo de inducir a la lectura de 'contemponaneidad' y de 'actualidad' en las obras, y de ser reconocidos como autores vigentes y 'modernos', ha llevado en Chile a las obras de arquitectura a exhibir -en todas las épocas- una contemporaneidad adjetiva y no sustantiva, con escasas excepciones. Adoptar signos para luego adaptarlos con una variación modelística y no con una reformulación dentro del tipo, hacen que los transplantes se sientan como copia a veces caricaturesca.

Hoy, momento en que la filosofía y arte contemporáneos reponen la licitud de la pregunta en el desafío de lo no resuelto; que cuestionan las representaciones dando valor a la 'presentación'; que desafían a incorporar las propias fuerzas e historias del observador, ofreciéndole lo ambiguo, las múltiples lecturas, la descentración de los significados y la exploración de las formas y los materiales, entre otros, las adopciones / adaptaciones modelísticas resueltas a priori resultan desconcertantes.

No se puede desconocer, sin embargo, que hay escasos originales y otros tantos que, aun teniendo referentes conocidos, sus adaptaciones son adecuadas al clima e idiosincracia locales. Mientras las adaptaciones modelísticas en el mejor de los casos, alcanzarán el nivel de evolución bajo nivel de la taxonomía creativa), las adaptaciones que trabajan más libremente un tipo pueden ser reconocidas como innovación. 


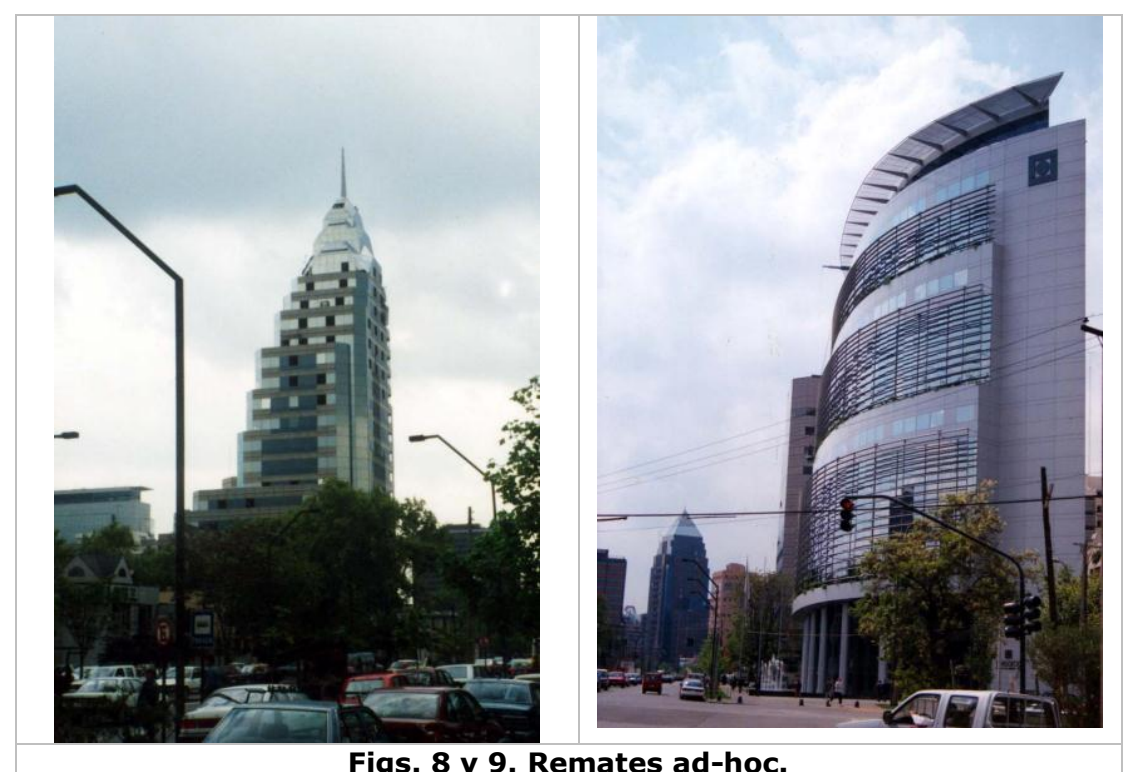

Figs. 8 y 9. Remates ad-hoc.

¿Cómo aprovechar esta capacidad de adopción y de variación modelística, sin insistir en la noción del tipo -que es estructural- aceptando la realidad actitudinal de la Identidad?

¿Aceptamos ejercitar 'citas' textuales, haciendo explícito su origen y factores, con toda humildad y transparentando y haciendo honesto su empleo escolar?

Debemos aceptar que un ejercicio riguroso de la 'cita' -similar al que se acostumbra en investigación- lleva de seguro reconocerlo y a sopesar cada factor que le dio origen, conduciendo a reflexiones sobre los nuevos factores ambiente en que debe insertarse $y$, desde allí, a transformaciones e innovaciones, (como lo reconoce hidalgamente James Stirling quien, durante sus primeros años de profesión, habría 'copiado' con admiración a Le Corbusier, incapaz de sacudirse su influjo).

4.- EI REMATE SUPERIOR es el signo más interpelante y significante para el chileno: comparado con otros niveles semáticos (accesos, esquinas, envolvente), los remates o 'techos' resultaron ser los primeros en develar el significado, relegando los otros signos a una afonía. Parece que se le presta éste mayor atención en etapa de proyecto, ya que no evidencian el mismo desarrollo y menos nivel de claridad o propósito.

Este es un hecho relevante, digno de tener en cuenta. 


\section{EI CLIMA NO ES EN CHILE CENTRAL UN INDUCTOR de codificación ni de} decodificación: el uso de la tipología 'techo de aguas' y 'techo plano' por ejemplo; o de accesos escuetos y directos o intermediados por alguna forma de umbral, resulta aleatorio, respecto a la localización en la Zona Central, cuya pluviometría varía entre $33 \mathrm{~mm}$ y $1.500 \mathrm{~mm}$, y también en alto grado su temperatura y vegetación. Contiguos unos a otros encontramos signos que significan en la memoria uno u otro, sin encontrarlo inadecuado, pero asignándolos correctamente si se presentan en una imagen. La noción de coherencia del signo y la idea de pertenencia adecuada están presentes, pero la sensibilización a su presencia incoherente se ha hecho laxa.

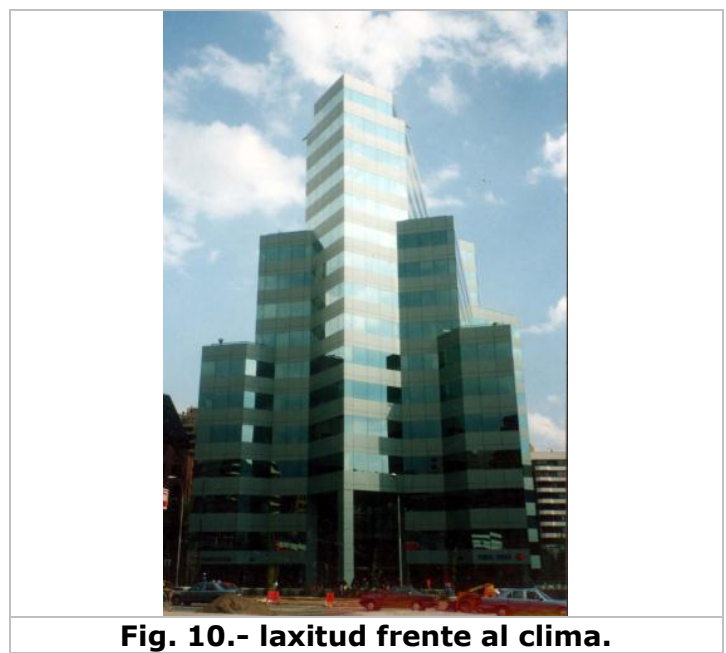

¿Podremos incorporar dedicar reflexión al efecto perceptual significativo del Remate Superior y de su efecto en la imagen y lectura urbana?

¿Estamos dispuestos a prestar mayor consideración al clima, en cada localidad particular -que en épocas es bastante marcado- sin asumir que un clima definido como templado 'aguanta todo'?

6. La economía de los 'LUSTRINES', su truncamiento como RASGO PROPIO: lleva a la reflexión el hecho de que el único rasgo que se identificó como 'propio', fuesen esos reiterados 'truncamientos' de prismas que la gente llama 'lustrines'. Se practican profesionalmente pero están ausentes de las aulas académicas. Obedecen a la forma posible dictada por la normativa de asoleamiento, pero no se ejercitan durante la formación. 


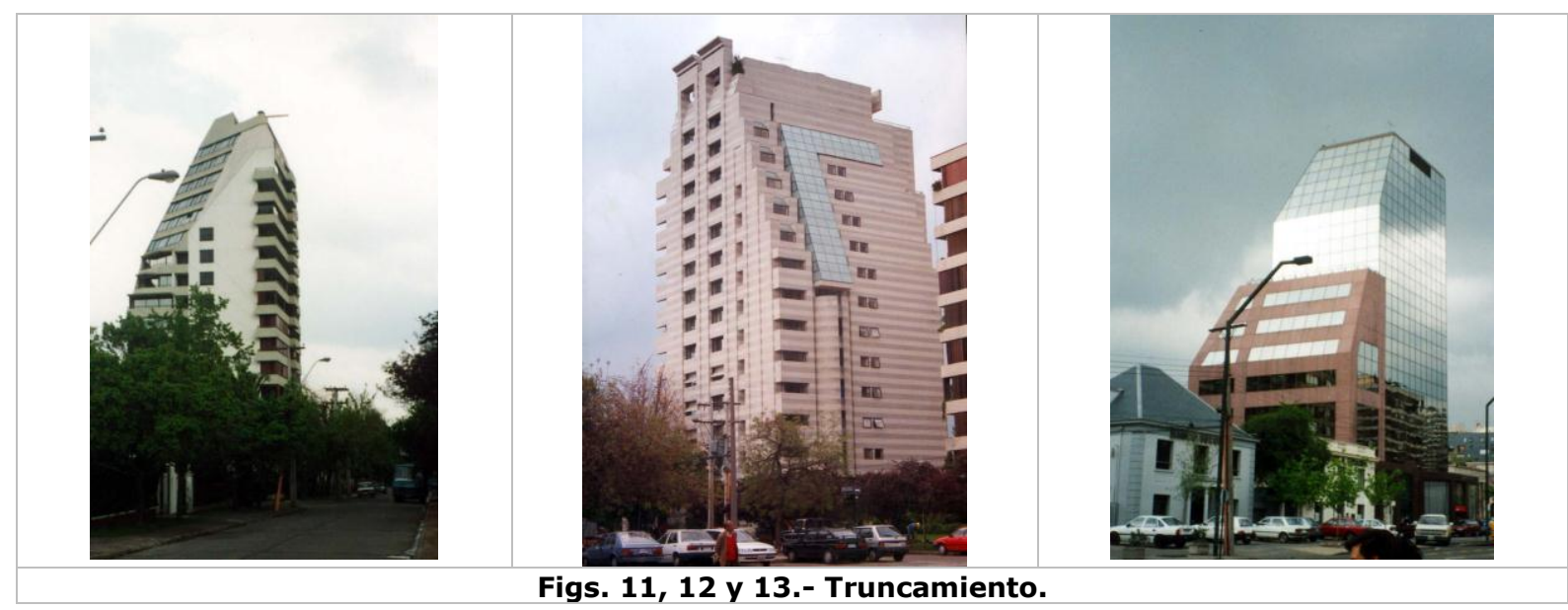

Mirar positivamente este recurso, y no rechazarlo desde la academia, contribuiría sin dudas a mejorarlos y de paso a dar identidad propositiva a la Imagen Urbana, pudiendo por ello llegar a constituirse en un 'término de intercambio', para instalarnos desde un Yo en el diálogo regional.

7.- SIMPLIFICACIÓN SIGNIFICATIVA REDUCTIVA: detectamos finalmente, por una parte, una fuerte 'cardinalidad' (seguramente debida a habitar un territorio largo y angosto, 'unidimensional') y una consecuente polaridad en la asignación de contenidos, donde se distinguen los polos y no los matices (norte/sur; costa/montaña; claro /obscuro); simultáneamente, la operación de un mecanismo de IDEALIZACIÓN que no considera -según lo mencionado- la realidad del clima; y, por último, una capacidad para autonomizar los elementos sintácticos y leerlos aisladamente como sintaxis autónomas. Estos mecanismos de simplificación condicionan la formación de códigos clausurados y dan cuenta de una actitud de 'lectura visual' particular.

Creemos que estos ocho rasgos pueden ser potenciados hacia niveles más altos de creatividad, si se atiende, al menos, a tres grandes aspectos desde la docencia:

a) Afinar la percepción de los matices intermedios de este largo territorio:

- Re-conocimiento de cada lugar, revisando la preconcepciones que se tiene.

- Mayor consideración al clima, con las tecnologías y la adecuación formal.

- Sensibilizar y cultivar otras experiencias de registro, más allá de lo visual.

b) Ampliar la reflexión y comprensión de las importaciones.

- Reconocer las referencias, factores y contexto físico y cultural de los signos.

- Entender la regla del signo antes que los atributos visuales de su sustancia.

c) Trabajo de significación contextualizada. 


\section{RUVSTADE URBANISMO \\ http://revistaurbanismo.uchile.cl}

- Mayor reflexión sobre los remates superiores, en texto, contexto y co-texto.

- Mayor desarrollo de otros niveles semáticos

- Promover la lectura integral en diferentes niveles de escalamiento y articulación interescalar.

Si la Identidad nos preocupa ahora es porque creemos que no está tan clara para la disciplina; si no se ha buscado antes tal vez sea porque no parecía importante al gremio. Lo encontrado $-y$ demostrado-, que no existe lenguaje arquitectónico como tal ni identidad suficiente entre nosotros, puede sin embargo, ser útil para quienes comparten la esperanza de que cuando en la docencia hablemos de nuestro hacer como 'lenguaje' o de 'identidad', nos detengamos un momento y acordemos de qué estamos hablando.- 